\title{
PRIMITIVE NEUROECTODERMAL TUMOR OF PARANASAL SINUS: A CASE REPORT
}

S. Yogesh ${ }^{1}$, Vidhyashankari², Dinesh Kumar ${ }^{3}$

\section{HOW TO CITE THIS ARTICLE:}

S. Yogesh, Vidhyashankari, Dinesh Kumar. "Primitive Neuroectodermal Tumor of ParanasalSinus- A Case Report”.Journal of Evolution of Medical and Dental Sciences 2013; Vol. 2, Issue 52, December 30; Page: 1020110203.

INTRODUCTION: Primitive neuroectodermal tumor (PNET) is a neural crest tumor ${ }^{1}$. It is a rare tumor, usually occurring in children and young adults under 25 years of age. The majority of the cells in the tumor are derived from neuroectoderm, but have not developed and differentiated in the way a normal neuron would, and so the cells appear "primitive. Many of these tumors are given a separate niche on the basis of the assumption that these embryonal tumors also could arise from cells already committed to differentiation. Jones and McGill reported 11 of 26 patients with disease in the head and neck ${ }^{2}$.Most other large published series, however, reveal a paucity of cases in the head and neck region ${ }^{3,4,5}$. Clinical symptoms depend on the site of presentation but invariably include pain and swelling of the surrounding structures due to mass effect.

CASE REPORT: A 6yr old female child presented with complaints of protrusion of right eyeball and right nasal obstruction for a period of two months, it was associated with a history of trauma in the past. Patient underwent a complete clinical examination, CECT PNS and orbit followed by routine investigations including, complete haemogram, HIV, HBsAg and B scan. On examination proptosis of right eye was seen, ocular movements were normal, visual acquity was normal. CT reported a $3.3 \times$ $2.3 \times 4.6$ enhancing expansile lesion involving right ethmoidal sinus, right nasal cavity, right maxillary sinus medial wall and nasal septum, erosion of the sinus wall and base of skull noted. The lesion was extending to the orbit and compressing the orbit and into the base of skull and sphenoid sinus. We planned for endoscopic sinus surgery under general anesthesia.Intraoperatively, smooth bulge was noted in middle meatus and posterior ethmoid area, uncinectomy was done ethmoid cavity was opened no air cells were seen, biopsy was taken for histopathologicalexamination.It was reported as round cell tumor. Immunohistochemistry was done positive for MIC-2 and neuron specific enolase and reported as primitive neuroectodermal tumor. Patient was treated with multiagent combination chemotherapy. One year and six months of follow up no recurrence was noted it was confirmed by repeat CECT and nasal endoscopy.

DISCUSSION: Primitive neuroectodermal tumors (PNETs)are group of highly malignant tumors composed of small round cells of neuroectodermal origin that affect soft tissue and bone, found mainly in children and young adults. Stout first described PNET in 1918, as these tumors were thought to arise directly from nerves ${ }^{6}$.The pathologic and cytogenetic understanding of these tumors has significantly advanced over the last 25 years. Based on molecular cytogenetic analysis, primitive neuroectodermal tumors (PNET) are known to share the reciprocal translocations, most commonly between chromosomes 11 and 22. Primitive neuroectodermal tumors (PNET) often exhibit aggressive clinical behavior, with worse outcomes than other small, round cell tumors. Clinical symptoms depend on the site of presentation but invariably include pain and swelling of the 


\section{CASE REPORT}

surrounding structures due to mass effect. Other reported symptoms and signs are site specific, including individual cranial neuropathies, exophthalmos, epistaxis, nasal obstruction, anosmia, neck masses, and headache. In our study patient had proptosis of right eye and right side nasal obstruction for a period of 2 months. Kimber et al,in a review of 26 patients with PNET who were treated with chemotherapy, reported that patients with head and neck PNET had an intermediate prognosis 7 .In this study, primitive neuroectodermal tumor was diagnosed after histopathological examination andimmunohistochemistry, it was positive for MIC-2 and neuron specific enolase in IHC. Patient underwent six cycles of multiagentchemotheraphy inj.Vincristnie1mg i.v.pulse, inj.doxorubicin $30 \mathrm{mg}$, inj.cyclophosphomide $370 \mathrm{mg}$, injdactinomycin $20 \mathrm{micro}$ gm.Prognosis of the tumor depends on the presence of metastasis, infilterative nature, unfavourable location that prevents adequate resection, and young age (less than 4 years). In our study after 18 months of follow up, no recurrence was seen which was confirmed with CECT PNS and nasal endoscopy.

CONCLUSION: Primitive neuroectodermal of paranasal sinus is relatively unusal,it is highly malignant and aggressive tumor which is seen more often in children and young adults. Biopsyand immunohistochemistry helps in diagnosing the tumor, it is managed with multiagentchemothreraphy. Early intervention is needed for a good prognosis.

\section{REFERENCE:}

1. Mueller S, Chang S. Pediatric brain tumors: current treatment strategies and future therapeutic approaches. Neurotherapeutics. Jul 2009;6(3):570-86.

2. Jones JE, McGill T. Peripheral primitive neuroectodermal tumors of the head and neck. Arch Otolaryngol Head Neck Surg. Dec 1995;121(12):1392-5.

3. Jürgens $\mathrm{H}$, Bier $\mathrm{V}$, Harms $\mathrm{D}$, et al. Malignant peripheral neuroectodermal tumors. A retrospective analysis of 42 patients. Cancer. Jan 15 1988;61(2):349-57.

4. Kushner BH, Hajdu SI, Gulati SC, Erlandson RA, Exelby PR, Lieberman PH. Extracranial primitive neuroectodermal tumors. The Memorial Sloan-Kettering Cancer Center experience. Cancer. Apr 1 1991;67(7):1825-9.

5. Marina NM, Etcubanas E, Parham DM, Bowman LC, Green A. Peripheral primitive neuroectodermal tumor (peripheral neuroepithelioma) in children. A review of the St. Jude experience and controversies in diagnosis and management. Cancer. Nov 1 1989;64(9):195260.

6. Stout AP. A tumor of the ulnar nerve. Proc NY Pathol Soc. 1918;18:2-11.

7. Kimber C, Michalski A, Spitz L, Pierro A. Primitive neuroectodermaltumours: anatomic location, extent of surgery, and outcome. J Pediatr Surg. Jan 1998;33(1):39-41. 


\section{CASE REPORT}

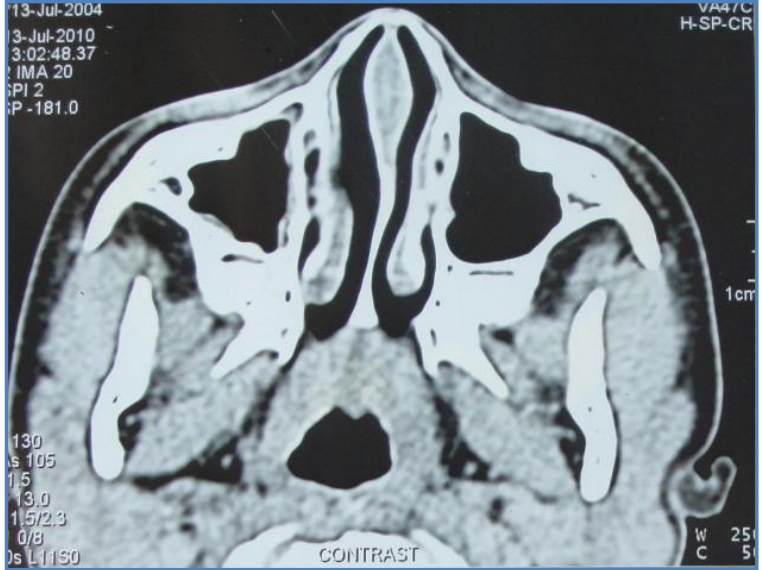

CT AFTER TREATMENT

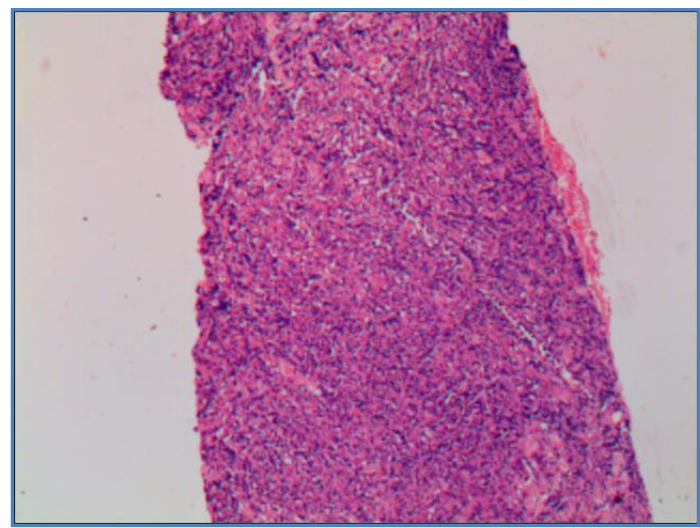

HIS 2

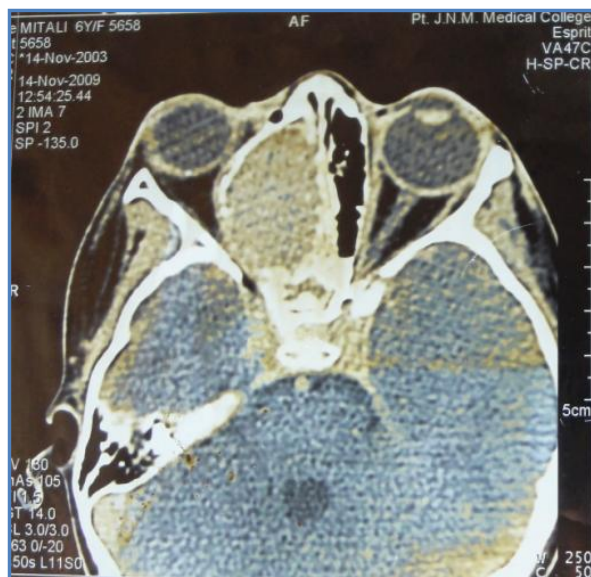

CT BEFORE TREATMENT

\section{AUTHORS:}

1. S. Yogesh

2. Vidhyashankari

3. Dinesh Kumar

\section{PARTICULARS OF CONTRIBUTORS:}

1. ENT Specialist, Department of ENT, Pt. JNM Medical College, Raipur.

2. Prosthodontist, Department of ENT, VMS Dental College, Salem.

3. Prosthodontist, Department of ENT, VMS Dental College, Salem.

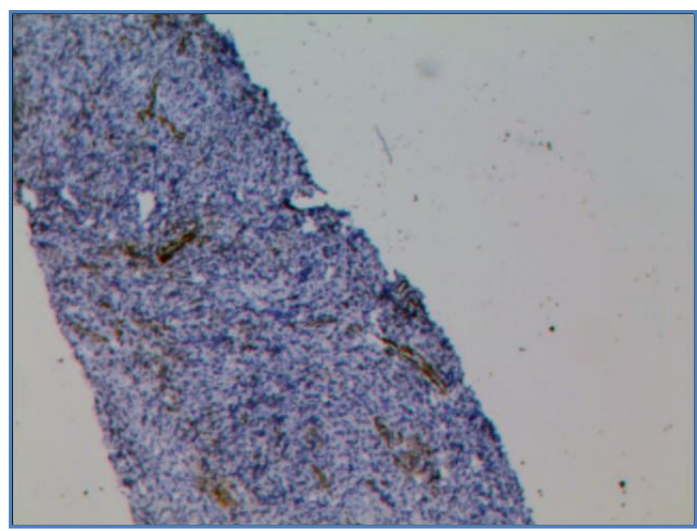

HIS

\section{NAME ADDRESS EMAIL ID OF THE CORRESPONDING AUTHOR:}

Dr. S. Yogesh,

5, K.T. Raju Street,

Raghupathi Naicken Palyam,

Erode - 638002, Tamilnadu.

Email-dryogesh_1512@yahoo.co.in

Date of Submission: 02/12/2013.

Date of Peer Review: 03/12/2013.

Date of Acceptance: 16/12/2013.

Date of Publishing: 26/12/2013 